\title{
Sharing One's Fortune? An Experimental Study on Earned Income and Giving*
}

\author{
Mirco Tonin ${ }^{\dagger}$ \\ Michael Vlassopoulos ${ }^{\ddagger}$ \\ University of Southampton, CEU, CESifo and IZA University of Southampton, IZA
}

March 2015

\begin{abstract}
In this paper, we investigate the relationship between earnings and charitable giving, in an environment in which earnings depend on luck but not in a manner that makes its contribution obvious. We set up a real effort experiment, in which subjects enter data in four one-hour occasions and are paid a piece rate. From the second occasion onwards, we randomly assign half of the subjects to a treatment with higher piece rates, without the subjects being explicitly made aware of the random assignment into the two groups. At the end we ask subjects whether they want to donate a share of their earnings to a charity of their choice. We find that, despite large differences in earnings due to the different piece rates, subjects receiving the higher piece rate are actually less likely to give, and that givers in the two groups give the same share of their total earnings. Charities receive the same average donation from members of the two groups, indicating that charitable giving by subjects in this experiment does not increase with income. We discuss how these results can be explained by self-serving attribution bias.
\end{abstract}

Keywords: charitable giving, real effort experiment, earned income, luck, windfall income $J E L:$ D64, J39

\footnotetext{
${ }^{*}$ This work was supported by the Economic and Social Research Council [grant number RES-061-25-0461].

${ }^{\dagger}$ Department of Economics, School of Social Sciences, University of Southampton, Southampton SO17 1BJ, United Kingdom. UniCredit Foscolo Fellow, CEU, Budapest. Email: m.tonin@soton.ac.uk

${ }^{\ddagger}$ Department of Economics, School of Social Sciences, University of Southampton, Southampton SO17 1BJ, United Kingdom. Email: m.vlassopoulos@soton.ac.uk
} 


\section{Introduction}

The relationship between an individual's income and charitable giving is a topic of great concern for policy makers and charities alike. For policy makers it is interesting because it informs the design of tax policy vis-a-vis charitable contributions. For charities it is relevant because it informs them on how to best focus their fundraising efforts. Both intuition and economic theories of giving predicated, for instance, on the notion that people derive some joy from the act of giving (Andreoni 1989, 1990), suggest that we should expect people with higher income to give more, in absolute terms, provided giving is a normal good. In fact, the evidence from the US is suggestive of a Ushaped relationship between household income and the percentage given to charity (e.g. Andreoni 2006), and of a positive income elasticity of charitable giving (e.g. Auten et al., 2002), while the evidence from experimental studies is mixed (Andreoni and Vesterlund, 2001; Buckley and Croson, 2006; Eckel et al., 2007; Erkal et al., 2011). There has also been a recognition that the donor's source of income may play an important role in the decision to give. In particular, people may feel more inclined to share with others if income is due to good luck rather than effort. ${ }^{1}$ There is indeed a robust finding in the experimental literature showing that in dictator games people are less likely to share earned income compared to windfall income (Hoffman et al., 1994; Ruffle, 1998; Cherry et al., 2002; Cherry and Shogren, 2008; Oxoby and Spraggon, 2008; Carlsson et al., 2012). ${ }^{2}$ A few recent experimental studies (Erkal et al., 2011; Rey-Biel et al., 2011), to be discussed in detail further on, go one step further by examining giving when income is determined partly by effort and partly by a random element. However, one aspect that has been largely neglected in this literature is that, in reality, while income is determined by different factors, including skills, effort, and luck, it is often not straightforward (with the exception of marginal events like lottery winnings) to clearly identify the role of luck. Moreover, in most instances good luck needs to be combined with some effort to bear fruits. For example, whether I get a big performance-related bonus at the end of the year depends probably on a combination of my effort and some exogenous factors (e.g. market performance, idiosyncratic shocks), ${ }^{3}$ but even in a booming economy I need to put some effort to be successful.

In this paper we explore whether people who earn a higher income are more likely to give, in an environment in which earnings depend on luck but not in a manner that makes its contribution

\footnotetext{
${ }^{1}$ It has also been found that people are more likely to share when recipients have or are believed to have low income due to bad luck rather than because of lack of effort, and that this may explain the differences in redistributive policies between the US and Europe (Alesina and Angeletos, 2005; Benabou and Tirole, 2006; Fong, 2007).

${ }^{2} \mathrm{~A}$ possible explanation for this is that an individual's sense of entitlement over income is related to his contribution in generating it. This perspective is consistent with the accountability principle, a rule of justice according to which a person's perception of a fair allocation is sensitive only to factors that he can influence (Konow, 2000; Cappelen et al., 2007). Gill and Stone (2010) apply a similar principle by assuming that an agent's perceived entitlement in a tournament competition is sensitive to how hard she has worked relative to her rival.

${ }^{3}$ Bertrand and Mullainathan (2001) provide empirical evidence that for CEOs pay is as responsive to luck as it is to performance.
} 
obvious, nor are they independent of effort, as good luck must be complemented with effort to generate income. To do this we design a real effort experiment, in which participants perform a data entry task on four hour-long occasions that take place within the course of a week and their pay depends on performance. Participants are told that the piece rate they will receive may vary from session to session and that it does not depend on performance in previous sessions. In particular, in the first occasion all subjects receive the same piece rate. In the second occasion we randomly split participants into two groups and, in the remaining three occasions, participants in the first group (low compensation group) keep working under the same piece rate, whereas participants in the second group (high compensation group) work under different piece rates in each of the three occasions, which are always higher compared to that of participants in the first group (and to what they received in the first occasion). At the end of the experiment, we ask participants whether they want to donate a percentage of their earnings to a charity of their choice. ${ }^{4}$

It is worth highlighting here the role of perceived luck in our experimental design. Participants are not aware of the actual random draw that determines whether they are in the low or high compensation group. Because of this, they do not observe the counterfactual pay they would have experienced with a different draw and it is not obvious to them whether they are actually lucky or not. Participants in the high compensation group, for instance, experience an increase in the piece rate compared to the first session, so they might think that the environment is rather favourable, but they do not know that they could have ended up with a flat piece rate, as was the case with half of the participants. If they at all think about a counterfactual, they might think about one involving a piece rate even higher than what they actually experience. So, they cannot say for sure whether they were lucky or not. Similarly for participants in the low compensation group. Thus, much like in real life, participants in our experiment know whether their situation is improving or stable, but they do not know exactly the counterfactual, so it is not obvious whether in their current circumstances they have been lucky or not. We then investigate whether the propensity to give to a charity out of earned experimental income depends on the treatment, that is, on the fact that compensation was generous, controlling for how hard the participant has worked on the data entry task.

We find that, despite large differences in earnings due, almost entirely, to different piece rates subjects in the high piece rate group earn on average three times more variable pay than those in the low piece rate group - the propensity to give is actually lower for those with higher earnings, albeit this difference is statistically only marginally significant. Moreover, conditionally on giving, the average proportion of earnings donated across the two groups is the same. As a result, charities

\footnotetext{
${ }^{4}$ The closest real-world parallel to our setting is the so-called "payroll giving", a scheme whereby employees sign up to donate a part of their salary to charity each month. For instance, in the UK 735,000 employees donated almost £118 million through payroll giving during the 2011/12 fiscal year (http://www.payrollgivingcentre.com/facts20figures.htm).
} 
receive the same average donation from members of the two groups indicating that charitable giving is not increasing with income.

Why is it the case then in our experiment that earning more because of luck - receiving a generous piece rate - does not translate into more generous charitable donations? After all, this is what one might have expected in light of previous experimental evidence suggesting that individuals give more when their endowment is windfall rather than earned. This outcome may be imputed to the notion of self-serving attribution bias, the human tendency to attribute good outcomes to own actions, rather than to external factors such as luck, that has been well-documented by psychologists (Miller and Ross, 1975), and has been invoked in economics to explain behavior in a variety of settings (Babcock and Loewenstein, 1997). In our experiment, a process of self-serving attribution - facilitated by the fact that in our design the role of luck in assigning subjects to groups is not explicit and subjects are unaware of the counterfactual - may lead subjects in the high piece rate group to downplay the role of luck for the higher earnings they receive, even if in reality the difference in earnings between the two groups is mostly due to exogenous factors. In turn, this distorted feeling of entitlement may furnish subjects in the high piece rate group the moral ground not to act more generously. This reasoning is related to the notion that people take advantage of "moral wiggle room" to act self-interestedly as shown in Dana et al. (2007). They found that, when there is uncertainty about the relationship between a dictator's actions and outcomes, subjects choose more frequently the selfish action. In our setting, the "moral wiggle room" is provided by the lack of transparency over the role of luck in determining the donor's earnings.

Our study is related to Erkal et al. (2011). They find that subjects who rank first in a real effort tournament (and thus receive higher earnings) are less likely to give to their group members than those ranked second. The explanation they provide for this is that there is selection on other-regarding preferences, namely, selfish subjects tend to exert more effort and thus have higher earnings than other-regarding subjects. They also find, similarly to us, that in a treatment where both effort and luck determine outcomes people with good luck are not more likely to give, and in a treatment where luck only determines ranking, people ranking first are as likely to give as people ranking second, despite earning a third more. The authors call for future work to consider whether their results hold when subjects give to an actual charity instead of each other and when earnings are determined using a piece rate scheme, two features that our experimental design exhibits. Another related study is Rey-Biel et al. (2011); in the first stage of their experiment subjects earn their income (partially due to effort and partially due to luck), and then play a two-person dictator game. In one treatment dictators know the determinants of the recipients' income, while in the other treatment they only know the total amount. They run their experiment in Spain and in the US and find that Spanish subjects give more when they get luckier, while Americans do not 
condition their giving on their own luck and transfer a flat amount.

It is worth highlighting two features of the above two studies that differentiate them from our setting: first, the role of luck versus that of effort in determining own income is very transparent there, whereas in our design, as we highlighted above, subjects are unaware of the distribution of possible piece rates, so there is no explicit reference point to judge a certain realized piece rate as being fortunate or not. Second, giving is directed toward other experimental participants who also earn income in the experiment. This brings to the front distributional considerations, that are more subdued in our setting in which giving is "impersonal", taking place by donating to charities, whose worthiness is determined outside the experiment.

The structure of the rest of the paper is as follows: the next section describes the procedures and experimental design, while section 3 presents the results. The last section offers some concluding remarks.

\section{The Experiment}

Our experiment involves two stages: in the first stage subjects performed a computerized real effort task and earned performance-related compensation. In the second stage, subjects were asked what proportion of their earnings, if any, they wanted to donate to a charity of their choice. The real effort task, entering bibliographic records of published academic articles in an online repository platform, was designed to be effort-intensive and not cognitively challenging, so that it could be performed remotely online on the subjects' own computer and required little training. In the Appendix we provide a screenshot of the task page, illustrating the various fields in which subjects would enter the details of the articles that were uploaded on the bottom of the page. Subjects received instructions when they first logged in and a video describing the task at hand. The experiment was arranged in four one-hour work periods, which participants had to complete within a week at a time of their choosing. The only restrictions we imposed were that participants could perform only one session per day, and that they could log in between $8 \mathrm{am}$ and 10pm. Participants were recruited from the University of Southampton student body through email announcements.

Subjects received $£ 20$ for completing the experiment (equivalent to a $£ 5$ flat fee per hourly session), and a piece rate compensation for each correctly entered record. They were informed that the piece rate may vary from session to session but that neither the piece rate nor any other aspect of a given session depended on performance in previous sessions. They were also informed that payment would be contingent on completing all stages of the experiment. Subjects found out the applicable piece rate at the beginning of each session. In particular, in the first session, the piece rate was set at $2.5 \mathrm{p}$ for everyone. From session 2 onwards, we randomly assigned subjects 
into 2 groups: subjects in Group Low received the baseline piece rate of $2.5 \mathrm{p}$ for the remaining three sessions; subjects in Group High faced three piece rates in sessions 2-4: either 5p, 7.5p or $10 \mathrm{p}$ in random order. These variations in compensation were designed to estimate the elasticity of output with respect to the piece rate, and are used in Tonin and Vlassopoulos (2015). Table 1 shows for Group High the number of subjects in each of the possible 6 sequences. It is also worth noticing that the number of days it took to complete the task is very similar between Group Low (5.2 days on average) and Group High (5.1 days on average) and a $\chi^{2}$ test fails to reject the null of no association between group and number of days ( $\mathrm{p}$-value $=0.93$ ).

Thus, to summarize, subjects in Group Low faced the same piece rate throughout, whereas subjects in Group High experienced 4 different piece rates: the same as Group Low in the first session, and higher ones from sessions 2 onwards. At the end of the fourth session, we informed subjects of their total earnings from participating in the experiment, and asked them whether they wanted to donate a percentage of their total earnings to a charity of their choice from a list of 9 with various missions (see Appendix for the list of charities). ${ }^{5}$ It should be noted that to avoid selection effects of the type found in Erkal et al. (2011) subjects were not aware of this possibility of donation at the work stage of the experiment. In this paper we focus on whether the decision to donate at the end is affected by earnings, and in particular on whether receiving higher earnings by virtue of having been assigned into the group with higher piece rates induces higher donations.

\section{Results}

Our analysis is based on a sample of 104 subjects - 52 subjects in each condition. ${ }^{6}$ We begin by presenting in Table 2 summary statistics of subjects' productivity on the real effort task in each session and for each group separately. We use two measures of productivity, correct and completed number of records entered. ${ }^{7}$ Accuracy, defined as correct entries divided by completed entries, is on average 0.93 (s.d. 0.08) for both groups (Mann-Whitney - henceforth MW - two-tailed test, p-

\footnotetext{
${ }^{5}$ Reported earnings were calculated on the basis of the total number of records entered. However, we informed participants that the amount of actual earnings they would receive would be based on the number of correct records they had entered, which we would verify later. This means that when subjects made the decision to donate they were aware of their reported earnings and not of their actual earnings, as payments were arranged by bank transfers after the experiment had ended. Our results are robust to using reported or actual earnings.

${ }^{6} \mathrm{~A}$ total of 8 subjects did not complete the whole set of sessions after being assigned to treatments. In particular, 5 subjects, 2 from Group Low and 3 from Group High, stopped after the second session, while 3 subjects, all from Group High, stopped after the third session. Using probit, logit or linear regressions we do not find any significant correlation between treatment group and the probability of dropping out after being assigned to treatment instead of completing the whole sequence. Therefore, we consider attrition bias not to be a threat to the validity of our results.

${ }^{7}$ Throughout the experiment subjects could see on their screen the amount of entered records within the session, while they did not receive any feedback regarding the number of correct records. This allows us, in Tonin and Vlassopoulos (2015), to assess whether incentives have a differential impact on quantity and quality. We find no evidence for that.
} 
value $=0.67$; Kolmogorov-Smirnov - henceforth KS - two-tailed test, p-value=0.97). The first point to note is that we cannot reject the hypothesis of equal distribution of productivity in session 1 across the two groups (KS two-tailed test, $\mathrm{p}$-value $=0.91$ for correct and $\mathrm{p}$-value $=0.29$ for completed entries), indicating that to start with there are no significant differences in the two groups' ability and desire to perform the task. In Tonin and Vlassopoulos (2015) we find that the 7.5p and 10p piece rates have a significant positive impact on relative performance, i.e. on the percentage change in the number of entries, while they also increase absolute performance, i.e. number of entries, for subjects with initial productivity below the median. However, when we consider total productivity by adding up the number of entries in all 4 sessions, we find that even if subjects in Group High enter on average $11 \%$ more correct records ( $12 \%$ completed records), this difference is not statistically significant (KS two-tailed test, $\mathrm{p}$-value $=0.43$ for correct and $\mathrm{p}$-value $=0.29$ for completed entries). In terms of earnings derived from working on the task (over and above the $£ 20$ flat fee), subjects in Group High earn substantially more than those in Group Low, £23.6 versus £8.3. This difference is statistically significant (MW two-tailed test, $\mathrm{p}$-value $=0.000$ ) and is almost entirely due to the fact that subjects in Group High are paid higher piece rates in sessions 2-4. To see why this is the case, note that if we keep the piece rate constant across the two groups at the baseline level of $2.5 \mathrm{p}$, then average earnings in Group High would have been £9.2. Thus, only $6 \%$ of the observed difference of $£ 15.3$ in earnings across the two groups can be attributed to differences in effort, while the bulk of it is in fact due to differences in how effort is compensated for exogenous reasons.

We next turn our attention to giving behavior. Figure 1 illustrates the histograms of amount donated as percentage of total experimental earnings by group. ${ }^{8}$ Table 3 presents descriptive statistics on the number of subjects who made a donation and on the average proportion of earnings given, both for the whole sample and among those who gave a positive amount. Table 4 presents descriptive statistics on the average amount of giving across the two groups, based on both reported and actual earnings. ${ }^{9}$

The first thing to notice from Table 3 is that the share of subjects giving zero is higher than what is usually found in dictator experiments, including studies in which endowments are earned (e.g. Hoffman et al., 1994; Cherry et al., 2002; Cherry and Shogren, 2008; Oxoby and Spraggon, 2008; Carlsson et al., 2012). ${ }^{10}$ The difference vis-a-vis experiments where the endowment is a windfall is not surprising. Compared to studies in which the endowment is earned, two distinctive

\footnotetext{
${ }^{8}$ There is an obvious outlier in the Low earnings treatment - a single individual who gives half of his or her earnings. The key results of lack of difference in likelihood of giving and share of earnings donated are not sensitive to the exclusion of this outlier.

${ }^{9}$ The most popular charity was Cancer Research UK, followed by the British Red Cross and Doctors without Borders.

${ }^{10}$ We have no reason to believe that this difference is due to a peculiarity of our sample per se. In fact, subjects recruited from the same subject pool to participate in dictator experiments have shown levels of giving that are similar to what is reported in the literature (Tonin and Vlassopoulos, 2014).
} 
features of our design are that the earnings-generating activity is more lengthy and taking place over the course of multiple days (four one-hour sessions instead of less than an hour in previous studies) and that earnings are not fixed but vary continuously with performance (while in previous studies subjects perform a task to earn some predetermined amount). Both of these elements are likely to increase the sense of entitlement of earnings in our experiment, and thus explain the lower likelihood to give we find. ${ }^{11}$

What is also evident in Table 3 is that there are more givers in Group Low than in Group High $(36.5 \%$ vs $21.2 \%)$ with the difference being marginally significant ( $\chi^{2}$ two-tailed test, $\left.p=0.08\right)$. Moreover, the average proportion of earnings given, among those who give, $8.7 \%$, is not different across the two groups. As a result, the average proportion of earnings given for the whole group (and not just among givers) is lower for Group High (1.8\%) than for Group Low (3.2\%), even if the difference is not statistically significant. In terms of amounts given, Table 4 indicates that on average charities receive the same amount from members of the two groups, with (the fewer) givers in Group High giving a significantly higher amount $(£ 4)$ than givers in Group Low (£2.3). This is true regardless of whether we focus on giving out of actual (columns 1,2) or reported earnings (columns 3,4).

We next turn to regression analysis that allows us to control for other possible determinants of giving, such as, total effort exerted on the task and gender. Columns 1 to 4 of Table 5 display regressions where the dependent variable is an indicator for whether a subject has donated, whereas in columns 5 to 8 the dependent variable is percentage given. It should be noted that from a theoretical standpoint, it is not clear whether we should expect someone who has earned a higher income because she worked harder - and not for exogenous reasons - to be more likely to give. This is because it may well be that the reason she worked hard was exactly to enjoy higher private consumption. What we see in Table 5 (columns 2 and 6 ) is that the total number of correct entries (measured in hundreds) is not an important determinant of the decision to give, and that the difference in proportions of givers across the two groups remains after controlling for productivity. Also, there is absolutely no indication that the decision on the percentage given is influenced by how hard the subject worked on the task. Finally, we see no evidence of differences in the percentage given across the two groups even after controlling for productivity. ${ }^{12}$ Results are almost identical when we use total number of completed entries as a measure of productivity. We also find no evidence of any gender effects (columns 3 and 7), as males and females in our sample do not behave differently.

\footnotetext{
${ }^{11}$ Incidentally, at an average of $2.5 \%$ of earnings for the whole sample, giving behavior in our experiment is actually very similar to the average percentage of income donated by Americans (Andreoni, 2006), and close to the average level of donations as share of household expenditures in the UK (Cowley et al., 2011).

${ }^{12}$ There are no differences across the two groups if we consider absolute amounts donated instead of percentages.
} 
One may be worried that the giving patterns of subjects in Group High may be driven by the sequence of piece rates experienced during the four sessions. In particular, subjects experiencing a drop in the piece rate in the last session may feel underpaid (or unfairly treated) and may be less likely to give than subjects who experience a rise. The change in the piece rate from session 3 to 4 may be particularly relevant as the giving decision takes place at the end of session 4 . To check whether this is the case, we include in the regressions (columns 4 and 8) a dummy indicating whether subjects experienced a hike in the piece rate when going from session 3 to session 4 . This happens in 3 out of the 6 possible sequences and splits Group High in two equally sized subgroups. ${ }^{13}$ We find no evidence that there is a significant difference between these two subgroups. We also investigated whether the piece rate experienced in the last session matters. Dummies for the piece rate experienced in the last session or a variable controlling for its value are all insignificant. Finally, when we add controls for earnings in the last session and/or total earnings we still find no differences in the likelihood of being a giver or in the percentage given across the two treatment groups.

All these results are robust to a logit or probit specification for the probability of donating or to a tobit specification for the percentage given. Also estimating a hurdle model in which the decision to give and the amount given are determined by two separate stochastic processes leaves the picture unchanged. Therefore, the regression analysis confirms the patterns emerging from the nonparametric tests reported above.

\section{Conclusion}

We conduct an experiment in which subjects first earn money working on a real effort task and are then offered the opportunity to make a donation to a charity of their choice. We find that varying exogenously the compensation received for exerting effort on the task does not induce high earners to be more generous towards the charities, even though it leads to large differences in earnings that are not related to effort. Thus, in our setting charitable giving does not appear to be increasing with income.

One could interpret the higher piece rates for Group High as a windfall that does not take the form of a lump sum payment but of an overly generous compensation package. However, we do not find that this windfall generates more giving, as it is instead the case in the previously mentioned literature that examines the effects of windfall and earned endowment on giving. One possible explanation for this is that subjects in our experiment exploit the uncertainty surrounding the contribution of luck in the determination of their earnings to construe as earned income what is in effect a windfall increase in their earnings. This distorted sense of entitlement then may allow

\footnotetext{
${ }^{13} \mathrm{~A}$ MW test indicates that there are no differences in total experimental earnings across these two subgroups of Group High.
} 
subjects who earn more to act less generously, compared to what would be expected from subjects who earn more out of sheer luck, without damaging their self-perception. Pushing this logic further by applying it to real life, where there is indeed ambiguity over whether effort or luck is responsible for someone's success, may at least partially account for the finding of a relatively flat relationship between share of income donated to charity and income (e.g. Andreoni 2006). ${ }^{14}$

Finally, our results have implications for the design of effective fundraising by charities. As the average donation collected from the two groups in our experiment is identical, it would seem that there is no sense for charities to target their fundraising efforts and resources solely toward high earners and disregard low earners. Of course, very high net-worth individuals, like Bill Gates, represent a very different category (Sadeh, Tonin and Vlassopoulos, 2014) and may well be worth extra attention from charities. Moreover, in reality, differences in earnings are due to a vast array of factors that are left out of our experiment, so this implication should be treated as only a step toward a better understanding of whether an individual's salary is a good indication of whether he will be an attractive candidate for providing support to a charitable organization.

\section{References}

[1] Alesina, A., and Angeletos, G.M. (2005). Fairness and Redistribution: US vs. Europe, American Economic Review, 95(4), 913-35.

[2] Andreoni, J. (1989). Giving with Impure Altruism: Applications to Charity and Ricardian Equivalence, Journal of Political Economy, 97(6), 1447-58.

[3] Andreoni, J. (1990). Impure Altruism and Donations to Public Goods: A Theory of WarmGlow Giving, Economic Journal, 100(401), 464-477.

[4] Andreoni, J. (2006). "Philanthropy," in S-C. Kolm and J. Mercier Ythier, eds., Handbook of Giving, Reciprocity and Altruism, Amsterdam: North Holland.

[5] Andreoni, J., and Vesterlund, L. (2001). Which Is the Fair Sex? Gender Differences in Altruism, Quarterly Journal of Economics, 116(1), 293-312.

[6] Auten, G.E., H. Sieg, and Clotfelter, C.T. (2002). Charitable Giving, Income, and Taxes: An Analysis of Panel Data, American Economic Review, 92(1), 371-382.

[7] Babcock, L., and Loewenstein, G. (1997). Explaining Bargaining Impasse: The Role of SelfServing Biases, Journal of Economic Perspectives, 11(1), 109-126.

\footnotetext{
${ }^{14}$ In a similar vein, Mayo and Tinsley (2009) argue that a donor's inability - which is a function of his income - to disentangle the role of luck and effort in determining the recipient's income is also important in explaining patterns of charitable giving in the US.
} 
[8] Benabou, R., and Tirole, J. (2006). Belief in Just World and Redistributive Politics. Quarterly Journal of Economics, 121(2), 699-746.

[9] Bertrand, M. and Mullainathan, S. (2001). Are CEOs rewarded for luck? The ones without principals are, Quarterly Journal of Economics, 116(3), 901-932.

[10] Buckley, E., and Croson, R. (2006). Income and Wealth Heterogeneity in the Voluntary Provision of Linear Public Goods, Journal of Public Economics, 90(4-5), 935-55.

[11] Cappelen, A.W., A.D. Hole, E. Sorensen, and Tungodden, B. (2007). The Pluralism of Fairness Ideals: An Experimental Approach, American Economic Review, 97(3), 818-827.

[12] Carlsson, F., H. He, and Martinsson, P. (2012). Easy come, easy go. The role of windfall money in lab and field experiments, Experimental Economics, forthcoming.

[13] Cherry, T., P. Frykblom, and Shogren, J. (2002). Hardnose the Dictator, American Economic Review, 92(4), 1218-1221.

[14] Cherry, T., and Shogren, J. (2008). Self-Interest, sympathy and the origin of the endowment, Economics Letters, 101(1), 69-72.

[15] Cowley, E., T. McKenzie, C. Pharaoh, and Smith, S. (2011). The new state of donation: Three decades of household giving to charity 1978-2008, Centre for Charitable Giving and Philanthropy.

[16] Dana, J., R. A. Weber, and Kuang, J. X. (2007). Exploiting moral wiggle room: experiments demonstrating an illusory preference for fairness, Economic Theory, 33(1), 67-80.

[17] Di Tella, R., S. Galiant, and Schargrodsky, E. (2007). The formation of beliefs: evidence from the allocation of land titles to squatters, Quarterly Journal of Economics, 122(1), 209-241.

[18] Eckel, C, P. J. Grossman, and Milano, A. (2007). Is More Information Always Better? An Experimental Study of Charitable Giving and Hurricane Katrina, Southern Economic Journal, $72(2), 388-411$.

[19] Erkal, N., L. Gangadharan, and Nikiforakis, N. (2011). Relative Earnings and Giving in a Real-Effort Experiment, American Economic Review, 101(7), 3330-48.

[20] Fong, C. (2007). Evidence from an Experiment on Charity to Welfare Recipients: Reciprocity, Altruism and the Empathic Responsiveness Hypothesis, Economic Journal, 117(522), 10081024.

[21] Gill, D., and Stone, R. (2010). Fairness and desert in tournaments, Games and Economic Behavior, 69(2), 346-364 
[22] Hoffman, E., K. McCabe, K. Shachat, and Smith, V. (1994). Preference, Property Rights and Anonymity in Bargaining Games, Games and Economic Behavior, 7(3), 346-380.

[23] Konow, J., (2000). Fair shares: Accountability and cognitive dissonance in allocation decisions, American Economic Review, 90(4), 1072-1091.

[24] Mayo, J., and Tinsley, C. (2009). Warm glow and charitable giving: Why the wealthy do not give more to charity? Journal of Economic Psychology, 30(3), 490-499.

[25] Miller, D. T., and Ross, M. (1975). Self-serving bases in the attribution of causality: Fact or fiction? Psychological Bulletin, 82, 213-225.

[26] Oxoby, R. J., and Spraggon, J. (2008). Mine and yours: Property rights in dictator games, Journal of Economic Behavior and Organization, 65(3-4), 703-713.

[27] Rey-Biel, P., R. Sheremeta, and Uler, N. (2011). (Bad) Luck or (Lack of) Effort?: Sharing Norms in the US and Europe, mimeo.

[28] Ruffle, B. (1998). More Is Better, but Fair Is Fair: Tipping in Dictator and Ultimatum Games, Games and Economic Behavior, 23(2), 247-65.

[29] Sadeh, J., Tonin, M., and Vlassopoulos, M. (2014). Why Give Away your Wealth? An Analysis of the Billionaires' View, Economics Department Discussion Paper 1417, University of Southampton.

[30] Tonin, M., and Vlassopoulos, M. (2014). An Experimental Investigation of Intrinsic Motivations for Giving, Theory and Decision, 76(1), 47-67.

[31] Tonin, M., and Vlassopoulos, M. (2015). Corporate Philanthropy and Productivity: Evidence from an Online Real Effort Experiment, Management Science, forthcoming. 


\section{Appendix}

\section{Screenshot of Task Page}

\section{Bibliographical Data Entry}

Time Remaining: 0 minute Bonus per record: $5 p$ Records Entered: 0

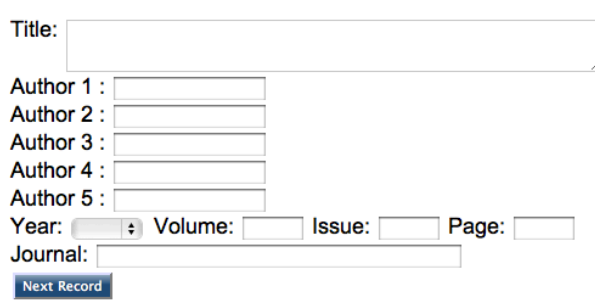

An Untapped Resource Using YouTube in Nursing Education

Agazio, Janice and Buckley, Kathleen M. (2009) An Untapped Resource Using YouTube in Nursing Education , NURSE EDUCATOR, Volume 34, Issue 1, Page 23-28

\section{Abstract}

Minimal information is available in the literature addressing video sharing in nursing education. Using Multiple examples, the authors discuss the use of YouTube, a popular video-sharing and social networking site. YouTube is used to illustrate theoretical content, involve students, and inspire innovative teaching methods. Faculty can use this technology to stimulate Student discussions, share information, and create a learning 